tagious diseases, which has operated without hardship to the individual and with much benefit to the community.

" So we had to content ourselves with those who submitted to the treatment of their own free will. In this way the disease (syphilis) will never be eradicated "

Thus spoke Dr. Langhorn in I788 in Denmark. Two and a half centuries later his fellow countrymen of Scandinavia have supplied positive proof of the wisdom of his words.

How long are we in this country to continue to provide the negative confirmation of this truth? We are frequently warned nowadays by the Government that we must guard against complacency whilst fighting for our lives. In relation to V.D., I, in turn, ask the Government to avoid complacency and to insure that we fight to preserve healthy lives.

\title{
REFERENCES
}

Burn, J. L., Lancet (I94I) 2, 655.

Quoted by EHLERS: Folkesyphilis i Danmark, Copenhagen, 1919, p. 7 I.

IV

\section{THE NEED FOR FURTHER POWERS TO DEAL WITH SOURCES OF INFECTION, CONTACTS AND DEFAULTERS}

Dr. E. W. Assinder said that compulsory powers should be given to local authorities or to their Medical Officer of Health but he did not think that compulsory powers alone when dealing with individuals would be sufficient. The most effective remedy would be compulsory notification with powers to local authorities to ascertain the doctor's methods of diagnosis and treatment and tests of cure. Also, in the case of contacts the doctor should be required to state what methods of examination had been used. He suggested compulsory notification coupled with the right of the M.O.H. to have access to the record card of the patient and compulsory powers for the local authority to be used when necessary.

Dr. A. MurRay Stuart desired education of the medical profession. He was undecided whether notification would drive the disease underground or be beneficial. In his area the health visitor who had been used to follow up defaulters had proved much better than the Almoner because she was well known in the streets and was recognised as legitimately visiting and could do very useful work.

Dr. J. L. BuRN described a scheme used in his area for two months in which out of 24 persons contacted, all promised to attend and actually r 9 did so. These I9 included 5 cases of gonorrhœa in an infectious condition and 8 of primary or secondary syphilis. No difficulty was found in the case of husband and wife or of man and woman living together in approaching the other party. Quite good results were obtained. The Salford City Council had passed a resolution which called for compulsory examination and/or treatment of contacts. He hoped there would be more such resolutions.

Mrs. Nevilie Rolfe thought that one of the factors in the success of the Scandinavian scheme was the additional two years' training of medical practitioners. Qualification to practise in Sweden included the equivalent of our postgraduate course in venereal diseases. One of the causes of the good results in the rural areas was the additional special training of every doctor before he took a rural appointment. Another big advantage was the compulsory inclusion of 


\section{THE BRITISH JOURNAL OF VENEREAL DISEASES}

hygiene in elementary education in Sweden. Every child leaving school at sixteen was fully informed of the physiology of reproduction and the incidence of venereal disease.

The voluntary system had failed in this country, on the women's side, because the psychological and sociological implications of venereal disease had been ignored. It was a serious position that the facilities for treatment for women were inadequate. To-day industrial populations were concentrated in areas out of reach of the existing clinics. The symptoms of gonorrhœa simulated the symptoms of other conditions. How could the lay woman know anything more than that she had a discharge and that she should seek medical care?

The speaker could not see that notification or compulsory treatment would be of much use until all medical practitioners could be relied on for diagnosis. The co-operation of the patient was needed in securing treatment and she believed in attracting people to treatment.

The voluntary scheme in this country failed to offer to women the type of facility they needed. The British Social Hygiene Council offered to one of the largest authorities in the country the services of a trained male almoner, who had worked in Toronto and New York, but the offer was turned down. The voluntary system could not be blamed when it had only been tried in that spirit.

The common objective was to reach all the infected and to safeguard the health of the future women and children of the country. There were five groups to be considered : wives, fiancées or those with one friend, " easy " girls, regularly promiscuous girls, and commercial prostitutes. To deal with the last two classes there must be, on social grounds, available in-patient accommodation. For the others, no system of notification would bring the individual girl under medical care unless she could come under an " umbrella" that did not stigmatise her. When treatment facilities improved and the women came under care, then the irresponsible, abnormal and subnormal persons of both sexes should be dealt with under compulsory powers for medical care.

She urged that the voluntary scheme should be made more effective and that the provision for women should be suited to their social and psychological needs.

Dr. W. G. Booth said that the powers they needed were not for notification but for treatment. In Sweden the penal clauses had not been used, and he believed that if similar powers were obtained in this country there would be no need to use them. Major Laird had suggested further education, particularly among "men in the street" and those in authority. But his experience in bringing the figures for V.D. before his council and hearing their discussion of the position, was that the man in the street (or his representative in the council chamber) needed no stimulating. The stimulus for action was coming definitely from the councillors in this country.

The difficult residue of cases was represented by the woman who was infecting four or five men and who declined the health visitor's advice to attend for treatment. If there was power to say, "You will be compelled to come if you do not come voluntarily" there would be no occasion to use the compulsory powers. He pleaded for some action to be taken as soon as possible.

Dr. R. ForGan suggested that the meeting should pass a resolution to the effect that further powers were required. He reminded the meeting that Scottish local authorities met year by year and passed almost unanimously resolutions calling for such powers. In I 928 Edinburgh Corporation attempted to get a Bill through for this purpose, but the attempt failed. The Scottish local authorities, however, had continued to press for further powers. Of course, these powers would be used only in the minority of cases, but their possession would be of enormous value. Venereal diseases were increasing. There was compulsion in the Services, why not compulsion for the civilians also?

It would be perfectly useless to allow ordinary general practitioners to certify that a patient was not suffering from venereal disease. Now that midwives had the right to call upon a doctor from a specially selected panel for obstetric cases, was it not a good precedent for having a similar panel of practitioners for the cases of V.D. ?

The Rev. J. D. Pearse-Higgins, C.F., said that he felt that individual clergy would be strongly in favour of Major Laird's proposal. As to how far the Church organisation would agree he could not say-he was not too optimistic. He had been struck by the attitude of the soldiers themselves to this problem for he had not met a man who resented the compulsion which the Army inflicted. On the general question he agreed strongly with the psychological approach. We were 
apt to expect people, especially women, to have more moral courage than they possessed.

Miss E. M. Turner said that the Association of Moral and Social Hygiene was against any form of compulsion and believed that the voluntary system had not been properly worked. Facilities were inadequate, medical education was inadequate and to submit people to compulsory treatment when there was no certainty that the standard of medical knowledge was equal to the occasion was rather unjust. Voluntary treatment should be continued but with improved facilities and a higher standard of medical education and that the Ministry of Health should increase their effort to bring to the people a knowledge of the venereal diseases.

She believed that compulsory treatment would prevent people from coming for early treatment. There was a distinct danger that people might be arrested and sent for treatment when they were not infected. The women who might infect four or more men should be compulsorily treated.

Dr. J. A. VINE said that he was heartily in favour of legislation. The problem of tuberculosis which had increased since the war, was similar to the problem under discussion. A committee presided over by Lord Horder made certain recommendations to the Government, particularly with regard to mass radiography of service entrants. The tuberculosis specialists in that instance were not adequately represented and those who were there were not sufficiently downright in putting forward their plans. He hoped that when this Society got to the committee they would not allow their representatives to be overwhelmed by people who were not particularly learned in the difficulties of this subject. He thought the time was ripe for legislation. There had just been a revolutionary regulation in connection with scabies and vermin. Legislation in respect of V.D. was much more essential, and it was the time to press forward as there might never be such a chance again. He begged them not to be overruled by wellintentioned and benevolent people in the House of Commons.

Dr. D. ERSKINE said that it was perhaps unfair to compare the Swedish system with that obtaining in this country because, in the first place, the outlook on sex in Sweden was quite different from what it was here. Education in hygiene was also further advanced. All clinic workers must see the advantages of notification, but if V.D. were notified the stigma was increased automatically and this would be a great handicap to the success of the voluntary scheme.

Dr. R. M. WARREN considered compulsory powers were necessary. He found that the troublesome patients were of two types: (I) the ignorant whom the medical officer and his staff could manage efficiently, and (2) the dangerous and obstructive who would not come for examination or treatment. Nothing but the threat of some penalty would make any impression on the latter type of patient. Any compulsion should be impartially applied to both sexes and all sections of the community including private and clinic patients.

Surg. Lieut.-Commander CoulTER, R.N. said that Major Laird should have added compulsory education; he did not think that education should be voluntary. The compulsory treatment of contacts and defaulters, he hoped, would be only a short term policy, and education when it was compulsory would remove the need for compulsory treatment.

Dr. R. P. A. MACAulay said that he, too, was in favour of legislation, but as there was a possibility that some infection might be driven underground by legislation he thought a wide publicity drive should be embarked upon before legislation came into force.

Lieut.-Col. A. J. King said that he had always considered that some powers of compulsion were desirable. Uncertain methods of treatment were tried out on a restricted number of patients, and therefore it seemed common sense that this suggestion, to which Dr. Forgan had referred in Edinburgh, should be tried out first by one local authority.

Dr. W. N. Mascall said that he was strongly in favour of some degree of compulsion especially for pregnant women. Certain homes had been established for this class where they were more or less compulsorily held, but no patient could be completely held there unless they were not quite mentally sound. He agreed that men also should be made to attend.

The President (Col. L. W. Harrison) said that the discussion had convinced him that the Scandinavian report was really better than he had imagined. One might imagine from what had been said by certain speakers as to the sufficiency of clinics that this was one of the most backward countries. Since the war 


\section{THE BRITISH JOURNAL OF VENEREAL DISEASES}

started great efforts had been made to encourage local authorities to increase their facilities, and they had been accompanied by an offer of 75 per cent. of the expense of any such increased facilities. This situation had been watched very carefully, and local authorities had been regularly written to with requests that they would afain consider the question of increasing the facilities. It would be astonishing to those present, if they looked at the records, to find how comparatively free from infection, as judged by the localities of infections of Service men, were the areas which were "backward " in respect of facilities.

Much had also been said about certain areas having inconveniently placed facilities which could not be made use of by women at work. He had looked into this matter and had got reports from medical officers of health. There was no denying that there were a number of bad cases, but a sense of proportion must be kept in this matter, and credit must be given to those concerned for carefully looking into the question from the local point of view. He was certain that the scheme for V.D. treatment was not as defective as suggested by certain speakers that afternoon, and he thought this country had got as good a scheme as any other.

As to notification, it must be agreed that notification was a "wash-out" so far as private practitioners were concerned. American records showed that only a small proportion of the private cases discovered by their censuses had been reported by private practitioners.

He joined issue with Major Laird on his comparison of Liverpool with Stockholm. Liverpool, for example, was nearer to South America than Stockholm was. The incidence of V.D. among seamen in ships trading with South America was far higher than among seamen in ships not touching that continent.

As for education in Sweden, when he and others were over there reporting on the Swedish system, they tried to discover what the man in the street thought about it. As far as they could gather, he did not seem to know much about the laws and regulations. But there was a far more realistic attitude on such matters in Sweden than we had here, and less false shame. For example, in a male clinic there were women nurses and he had seen a man irrigated by one of these.

Major LAIRD, in reply, said that he thought they all saw eye to eye in principle, with divergencies in detail. He had prefaced his plea for further powers by insisting on further education of medical practitioners. He wanted the voluntary method to be retained and to be as good as it could be, but he wanted also the power to deal with people with whom the voluntary system failed.

At the end of the meeting the following resolution was put to the large audience of members and was passed by an overwhelming majority :-

"That in the opinion of this meeting of the Medical Society for the Study of Venereal Diseases, further powers, legislative and administrative, in the treatment and prevention of venereal diseases are required to deal with sources of infection, contacts and defaulters."

\section{SOME ASPECTS OF THE SEROLOGY OF SYPHILIS, WITH SPECIAL REFERENCE TO ITS THEORETICAL AND PRACTICAL SIGNIFICANCE *}

By H. SACHS, M.D. (from the Department of Bacteriology, School of Pathology, Trinity College, Dublin).

THE problem whether the serological syphilis tests have an unequivocal diagnostic and therapeutic significance or if falsely positive results may also be obtained is recently again the object of discussion.

* With partial use of the writer's article "The Wassermann Reaction, etc." in the Irish Journ. of Med. Science, February, I94I. 